\title{
Scale-dependent correlation of sperm whale distribution with environmental features and productivity in the South Pacific
}

\author{
Nathalie Jaquet*, Hal Whitehead \\ Biology Department, Dalhousie University, Halifax, Nova Scotia, Canada B3H 4J1
}

\begin{abstract}
The purpose of this study was to investigate sperm whale Physeter macrocephalus distribution in relation to underwater topography, temperature gradients and primary and secondary productivity. The influence of these factors over different spatial scales ( 80 to 640 nautical miles) was examined, and the importance of food resources in determining sperm whale distribution was assessed. The data were collected during a survey around the South Pacific. Principal component analyses were used to assess the relationship between the environmental measures recorded and to relate them to sperm whale density. The first principal component was considered as an index of secondary productivity, the second as an index of underwater topography, and the third as a contrast between deep and surface productivity. Sperm whale density was correlated with the first and the second principal components over spatial scales equal to or greater than $320 \mathrm{n}$ miles. This result indicates that sperm whales are generally distributed within large areas which are characterized by high secondary productivity and steep underwater topography. The size of these areas may reflect the distances over which the groups of whales move in search of food. The absence of correlation over smaller spatial scales suggests that factors other than the distribution of food resources also influence sperm whale distribution over these scales.
\end{abstract}

KEY WORDS: Sperm whale Distribution Spatial scale - Temporal scale Principal component analyses. Chlorophyll concentration Sub-surface biomass Underwater topography

\section{INTRODUCTION}

The sperm whale Physeter macrocephalus has the most extensive distribution of any marine mammal species, rivaled in this respect only by the killer whale Orcinus orca. They range through all deep oceans of the world from the equator to the edge of the pack ice (Rice 1989). Most of the sperm whale's diet consists of meso- and bathypelagic cephalopods (Clarke 1966, 1980). Since methods of effectively sampling deep-living squid have not yet been developed (Clarke 1985), it has been impossible to relate sperm whale distribution to the distribution of its principal prey items. However: it is known that prominent bathymetry, temperature gradients of about $5^{\circ} \mathrm{C}$ in the upper hundred

\footnotetext{
•E-mail: njaquet@is.dal.ca
}

meters and the presence of oceanic fronts are important factors contributing to the concentration of squids and fish (Uda 1959, Green 1967, Murphy \& Shomura 1972, Gaskin 1973, Sutcliffe \& Brodie 1977, Greenblatt 1979, Selzer \& Payne 1988, Bakun \& Csirke in press). Therefore, several attempts have been made to relate sperm whale distribution to underwater topography (Clarke 1956, Kenney \& Winn 1987, Whitehead et al. 1992), sea surface temperature and temperature gradient (Gaskin 1973, Ramirez \& Urquizo 1985), and divergence or convergence zones (Gaskin 1968, Berzin 1971, Gulland 1974, Volkov \& Moroz 1977, Best 1979, Viale 1991). However, no attempt has been made to understand the spatial scales of these possible relationships.

Multiscale studies have been conducted on other marine organisms, and the results emphasize the 
importance of looking at a range of spatial scales. Schneider \& Piatt (1986) found that correlations between seabirds and schooling fish were scale dependent, as indicated by a significantly higher correlation coefficient at larger spatial scales than at smaller spatial scales. Similarly, Fairweather (1988) demonstrated that whelk Morula marginalba density was negatively correlated with barnacle Tesseropora rosea density over small spatial scales, and positively correlated over larger spatial scales.

There is no single scale at which sperm whale distribution should be investigated, but much is to be gained in understanding how the relationship between sperm whale density and environmental parameters varies with scale. Such studies could outline the range of spatial scales over which food resources are important factors influencing sperm whale distribution. However, as sperm whales are near the top of a very long food chain and feed at depths of 400 to $600 \mathrm{~m}$ (Gordon 1987, Papastavrou et al. 1989), other factors have also to be taken into account.

Clarke et al. (1993) demonstrated that sperm whales consume a very wide size range of cephalopods, feeding on squid of less than $100 \mathrm{~g}$ to squid over $100 \mathrm{~kg}$ They obtain about $77 \%$ of their food by swimming through luminescent schools of slow and neutrally buoyant cephalopods and about $23 \%$ by chasing faster and larger prey. Bakun \& Csirke (in press) argue that larval squid are accumulated in convergence zones. However, as most species of cephalopods descend to greater depth as they grow (Clarke \& Lu 1974, Lu \& Clarke 1975), the prey of sperm whales could be spatially displaced in relation to oceanic fronts. Moreover, surface observations may also be poor indicators of phenomena at depth. For instance, Volkov \& Moroz (1977) pointed out that the presence of a convergence zone at the surface does not mean that there is still a convergence zone $500 \mathrm{~m}$ below. As isopycnic surfaces are frequently inclined, there can be a considerable shift in space of the zone with increased depth.

The present paper investigates sperm whale distribution in relation to underwater topography, temperature and thermocline parameters, chlorophyll concentration and measures of sub-surface biomass at 4 different spatial scales. Scale dependent correlations between sperm whale density and environmental features are examined and the importance of food resources in determining sperm whale habitat is discussed.

\section{METHODS}

Field methods. Data were collected from a $12.5 \mathrm{~m}$, ocean-going cutter during a survey around the South Pacific in 1992 to 1993 (Fig. 1). A total of 184 d were spent at sea. Sperm whales were located by listening every half hour through an omnidirectional hydrophone for their characteristic clicks (Backus \& Schevill 1966). Since the survey track was designed to go through all major 19 th century sperm whaling grounds of the South Pacific (Townsend 1935), the sampling distribution of searching effort was not random. Once located, the sperm whales were usually followed both acoustically and visually for periods ranging from a few hours to $2 \frac{1}{2} \mathrm{~d}$.

During the entire survey, biological and environmental data were collected regularly. Chlorophyll concentration was measured every day at 15:00 h local time by a spectral radiometer (McLean \& Lewis 1991). The intensity and the thickness of scattering layers were recorded at 3 different depths every day at 15:00 h local time using a Furuno $\mathrm{CH} 14$ sonar (frequency: $60 \mathrm{kHz}$ ). The 3 depths were defined as follows: the surface layer, from 0 to $50 \mathrm{~m}$ deep ( depth of the euphotic zone); the middle layer, from 50 to $300 \mathrm{~m}$ deep; and the deep layer, from 300 to $600 \mathrm{~m}$ deep ( depth at which sperm whales normally feed; Papastavrou et al. 1989). To avoid solar heating effects, sea surface temperature was measured every day at 06:00 h local time. Temperature profiles were determined every 300 to 400 nautical miles (n miles) using expendable bathythermographs (XBT). The position of the boat was recorded every hour using a Trimble Transpak GPS.

In sailing around the South Pacific, the research vessel traveled through 4 main regions: (1) South American coast along the American Continent from Puerto Montt $\left(42^{\circ} \mathrm{S}, 74^{\circ} \mathrm{W}\right)$ to Panama City $\left(9^{\circ} \mathrm{N}, 79^{\circ} \mathrm{W}\right)$, to a longitude of $92^{\circ} \mathrm{W} ;(2)$ equatorial region along the equator from $92^{\circ} \mathrm{W}$ to the American Samoa $\left(13^{\circ} \mathrm{S}\right.$, $\left.170^{\circ} \mathrm{W}\right)_{i}$ (3) West Pacific region, west of $170^{\circ} \mathrm{W}$; (4) South Pacific gyre between $170^{\circ} \mathrm{W}$ and $92^{\circ} \mathrm{W}$, at a latitude of $30^{\circ}$ to $40^{\circ} \mathrm{S}$.

Data analyses. The track of the research vessel was divided into $80 \mathrm{n}$ mile segments $(=$ minimum distance traveled in $1 \mathrm{~d}$ ). For each segment, the variables described in Table 1 were calculated.

Both the variable 'density of whales' (denswhal) and the variable 'number of encounters' (nbrenc) measured sperm whale density. However, as about half the time sperm whales were tracked once located, denswhal is biased in favor of the areas where the whales were followed. On the other hand, nbrenc is biased towards the areas where whales were not followed. Therefore, each analysis was carried out separately with the 2 sperm whale variables.

The Contour Index (C.I.) was calculated using the charts 'Bathymetry of the North/South Pacific, Scripps Institution of Oceanography and Institute of Marine Resources, 1970' All segments were reported on the 


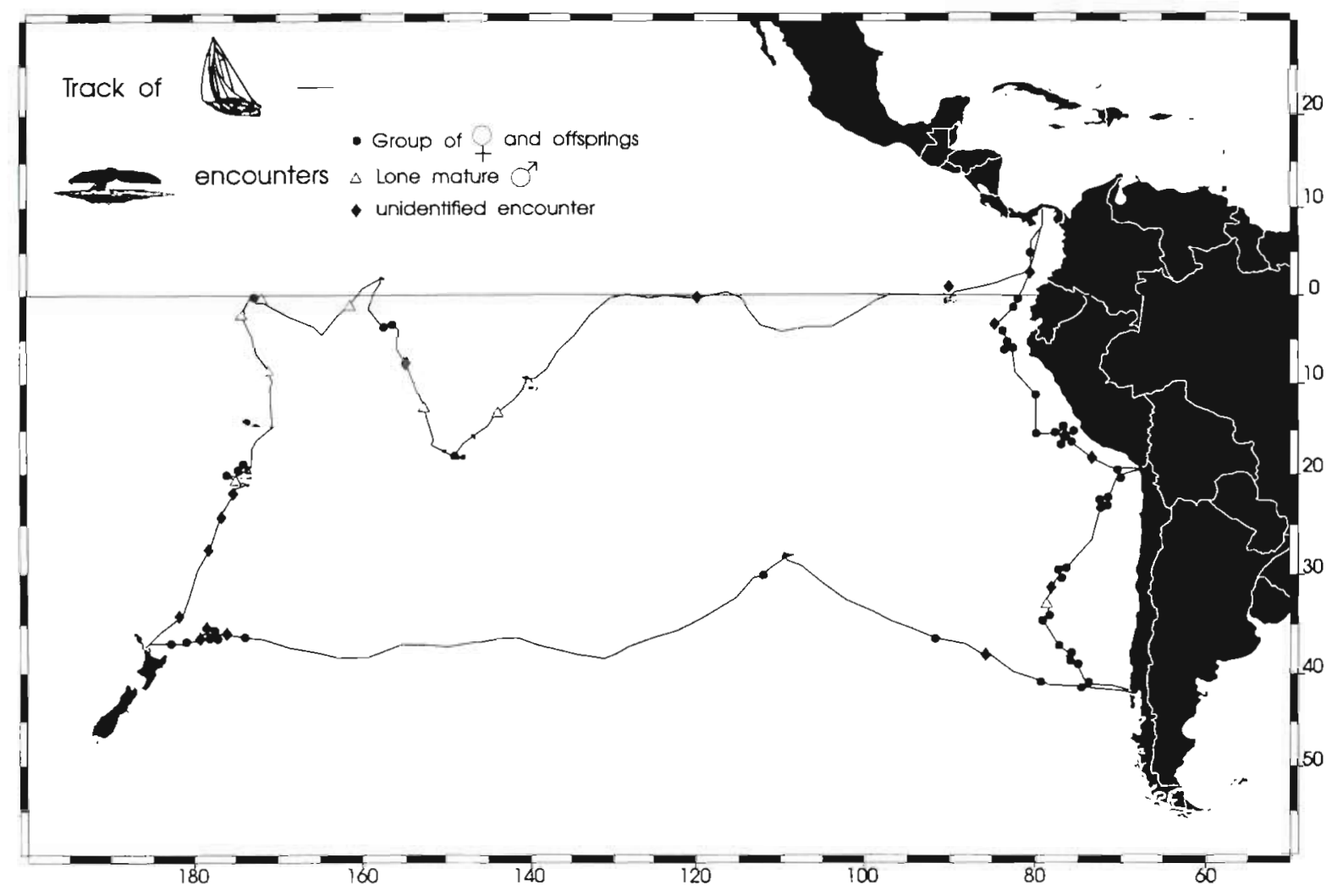

Fig. 1. Location in South Pacific showing the track of the research vessel and sperm whale encounters

Table 1. Description of the variables calculated for each segment

\begin{tabular}{|c|c|c|}
\hline Variable & Description & Units \\
\hline Denswhal & $\begin{array}{l}\text { Number of } 1 / 2 \mathrm{~h} \text { listenings during which we heard or saw whales divided by the } \\
\text { total number of } 1 / 2 \mathrm{~h} \text { listenings }\end{array}$ & $\%$ \\
\hline Nbrenc & Number of times we encountered a 'new' group of whales & - \\
\hline Chlconc & Chlorophyll concentration & $\operatorname{mg~m} m^{-3}$ \\
\hline Intmax 1 & Maximum intensity of the surface scattering layer $(0-50 \mathrm{~m})$ & $\begin{array}{l}\text { Subjective scale from } \\
\quad 0.00 \text { to } 4.00\end{array}$ \\
\hline Thick1 & Thickness of the surface scattering layer $(0-50 \mathrm{~m})$ & $\mathrm{m}$ \\
\hline Intmax2 & Maximum intensity of the medium scattering layer $(50-300 \mathrm{~m})$ & $\begin{array}{l}\text { Subjective scale from } \\
0.00 \text { to } 4.00\end{array}$ \\
\hline Thick2 & Thickness of the medium scattering layer $(50-300 \mathrm{~m})$ & $\mathrm{m}$ \\
\hline Intmax3 & Maximum intensity of the deep scattering layer $(300-600 \mathrm{~m})$ & $\begin{array}{l}\text { Subjective scale from } \\
0.00 \text { to } 4.00\end{array}$ \\
\hline Thick3 & Thickness of the deep scattering layer $(300-600 \mathrm{~m})$ & $\mathrm{m}$ \\
\hline$S S T$ & Sea surface temperature & ${ }^{\circ} \mathrm{C}$ \\
\hline DifinSST & Difference in sea surface temperature between 2 consecutive segments & ${ }^{\circ} \mathrm{C}$ \\
\hline$\Delta$ tmax & $\begin{array}{l}\text { Maximum difference in temperature between } 2 \text { consecutive measures }(\sim 65 \mathrm{~cm}) \\
\text { in the temperature profile }\end{array}$ & ${ }^{\circ} \mathrm{C}$ \\
\hline Depthst & $\begin{array}{l}\text { Depth of maximum difference in temperature between } 2 \text { consecutive measures }(-65 \mathrm{~cm}) \\
\text { in the temperature profile; corresponds roughly to the mixed layer depth }\end{array}$ & $\mathrm{m}$ \\
\hline Gradient & Gradient of temperature in the first $100 \mathrm{~m}$ & ${ }^{\circ} \mathrm{C} / 100 \mathrm{~m}$ \\
\hline Meandept & Mean ocean depth & $\mathrm{m}$ \\
\hline C.R. & $\begin{array}{l}\text { Contouir indox, dofino using Hui's }(1979) \text { formula, } \\
\text { C.I. }=100 \times[(\text { maxdepth }- \text { mindepth }) / \text { maxdepth }]\end{array}$ & - \\
\hline Distland & Distance to the closest shore, including all oceanic islands & n miles \\
\hline
\end{tabular}


charts, and the maximum and the minimum depth in a radius of half of the segment's length were used to calculate the C.I. according to Hui's formula (1979): C.I. = $100 \times[$ (maxdepth - mindepth)/maxdepth].

To increase the spatial scale, 2 segments were combined to make $160 \mathrm{n}$ mile segments, and then 320 and 640 n mile segments respectively. For each segment at each spatial scale all the variables listed in Table 1 were calculated.

The relationships within the biological and environmental variables and between the environmental variables and the density of whales were first investigated using correlation analyses. None of the untransformed variables were normally distributed, and transformations (mainly square roots, logarithmic and arc-sines) succeeded only in rendering normal a few variables over the largest spatial scales (Kolmogoroff-Smirnoff tests). Therefore, non-parametric Spearman correlation coefficients (Sokal \& Rohlf 1981) were used. However, as the data were collected each day along a survey track, most variables showed considerable autocorrelation with lags ranging from 1 to 20 segments. Once again, transformations (value difference between 2 segments) failed to remove the autocorrelations (ACF plots), reducing it to a lag of about 6 segments (at the $80 \mathrm{n}$ mile scale). As we were more interested in finding patterns and consistency in the patterns than in rigorously testing hypotheses, and as using only 1 segment out of 6 reduced the data set too drastically, all data were used for the correlation analyses but no significance test results are given. Correlation coefficients substantially greater than 0.25 or less than -0.25 were taken as indicators of a relationships.

As most of the environmental variables were strongly correlated, multivariate analyses were also used to investigate the relationship between sperm

Table 2. Summary of statistics for environmental variables over a spatial scale of $80 \mathrm{n}$ miles. Variables as in Table 1

\begin{tabular}{|lccccc|}
\hline Vanable & No. of cases & Min. & Max. & Mean & SD \\
\hline Chlconc & 149 & 0.06 & 8.72 & 0.46 & 0.86 \\
Intmax1 & 173 & 0 & 4 & 2.06 & 1.42 \\
Thick1 & 173 & 0 & 50 & 22.2 & 14.9 \\
Intmax2 & 173 & 0 & 4 & 2.85 & 1.20 \\
Thick2 & 173 & 0 & 250 & 130.1 & 59.3 \\
Intmax3 & 173 & 0 & 4 & 1.15 & 1.38 \\
Thick3 & 173 & 0 & 300 & 66.7 & 61.2 \\
SST & 171 & 15.2 & 29.5 & 23.6 & 3.75 \\
Dmax & 55 & 0.03 & 1.86 & 0.37 & 0.28 \\
Depth $\Delta t$ & 55 & 11 & 180.2 & 69.3 & 43.4 \\
Gradient & 55 & -0.7 & 11.96 & 5.60 & 3.54 \\
Meandept & 258 & 500 & 6000 & 3612 & 1123 \\
C.I. & 264 & 0 & 100 & 35.9 & 35.2 \\
Distland & 264 & 2 & 1400 & 317 & 340 \\
\end{tabular}

whale density and the environmental variables. Principal components analyses were performed on the correlation matrices of most of the environmental variables (if for a specified spatial scale a variable had too many missing points, it was deleted from the analysis). The resulting loadings provided a measure of association between each original variable and the resultant principal components. No multiple regression of sperm whale density on the various factors was carried out, as the normality assumptions were still violated (plot of residual versus estimate show non-constant variance of the residuali Flury \& Riedwyl 1988). Therefore, nonparametric Spearman correlation coefficients were calculated between sperm whale density and the principal components over each spatial scale

\section{RESULTS}

During the survey around the South Pacific, we encountered sperm whales 70 times. Of these, 8 encounters were with single mature males, 46 with nursery groups (including about 20 females and immatures of both sexes), and in 16 cases, the type of aggregation encountered was unidentified (Fig. 1). We listened 8332 times for the characteristic clicks of sperm whale, and in 1510 of these times whales were either seen or heard.

The track of the research vessel was divided into 264 segments of $80 \mathrm{n}$ miles. The summary statistics of the measurements of temperature parameters, chlorophyll concentration, surface, medium and deep biomass and bathymetry variables are shown in Table 2.

All statistical analyses were done using the 2 variables measuring sperm whale density (denswhal and nbrenc). But as they both gave similar results, only those using denswhal are presented here

No correlations greater than 0.2 , or less than -0.07 , were found between sperm whale density and any temperature variable (sea surface temperature, difference in sea surface temperature between 2 adjacent segments, depth and intensity of the thermocline, gradient of temperature in the first $100 \mathrm{~m}$ ) at any spatial scale. Similarly, no correlations greater than 0.24 or less than -0.08 were found between sperm whale density and chlorophyll concentration, or between sperm whale density and the thickness or intensity of the surface scattering layer at any spatial scale. However, the Spearman correlation coefficients between sperm whale density and the intensity and thickness of the middle and deep scattering layers showed substantial positive correlations over spatial scales of 320 and $640 \mathrm{n}$ miles (Fig 2A). There were also substantial positive correlations between sperm whale density and the C.I. at the 2 largest scales. Substantial negative 


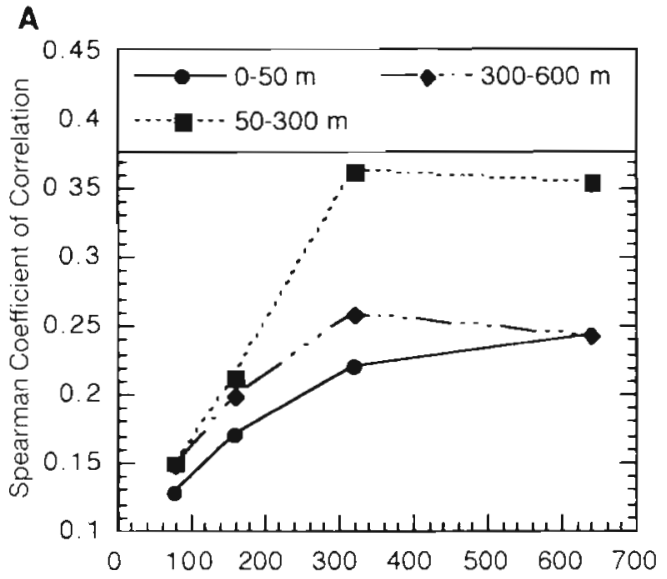

B

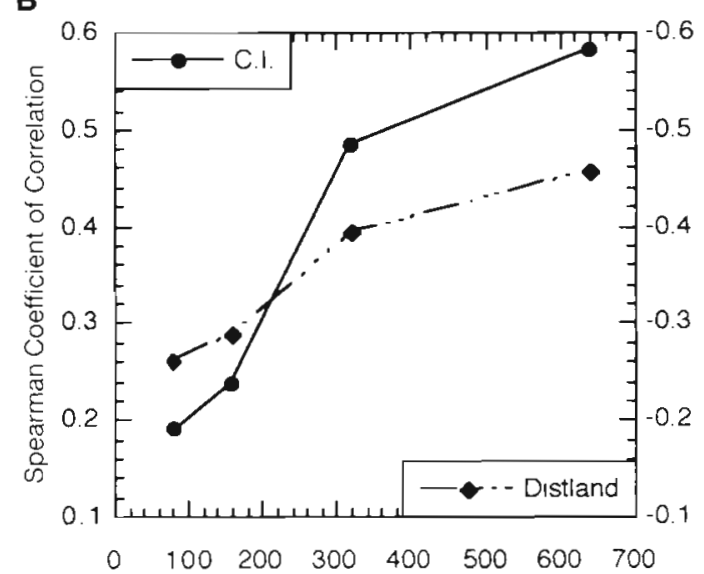

C

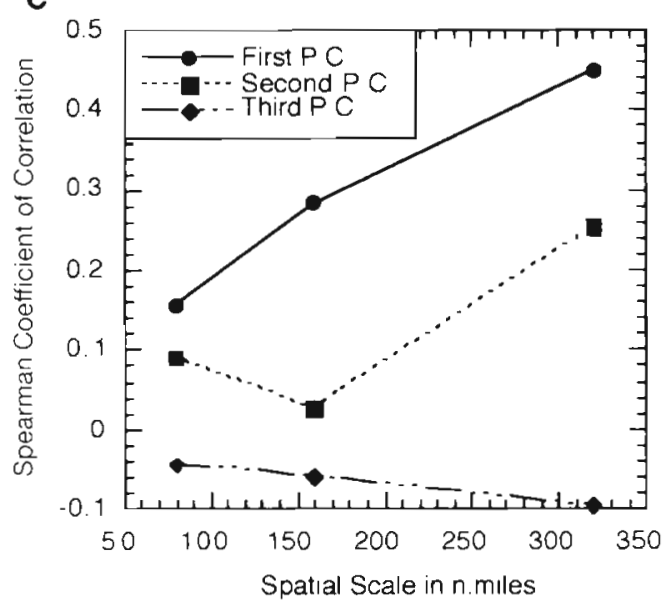

Fig. 2. Spearman coefficient of correlations between sperm whale density and (A) maximum intensity of the scattering layer at 3 different depths, (B) contour index (C.I.) and distance to the closest shore, $(C)$ the first 3 principal components (PC) of the environmental variables over a range of spatial scales

correlation between sperm whale density and the distance to the closest shore was also found only for the 2 largest scales (Fig. 2B)
As the Spearman coefficient of correlation could be dependent on the number of observations, the increase of its value with increasing spatial scale could therefore be an artifact resulting from smaller number of observations at larger spatial scales. To assess the relationship between the value of the coefficient of correlation and the number of observations, subsets of $20,30,40, \ldots, 210$ observations were randomly chosen from the largest file ( $80 \mathrm{n}$ miles). Spearman coefficients of correlation analyses were carried out for each subset and for the 5 relevant variables (intmax1, intmax2, intmax3, C.I., distland). The coefficient of correlation was plotted against the number of observations to investigate possible dependency. As the results showed no increase of $r_{S}$ with decreasing number of observations, and no other consistent trend, it was concluded that the patterns observed on Fig. 2A, B were not an artifact due to the methodology used.

The relationships within the environmental variables were further investigated by Principal Component Analyses (PCA). The 3 smallest spatial scales $(80,160$ and $320 \mathrm{n}$ mile segments) gave very similar principal components, with the component loadings being almost exactly the same. Therefore, only the results using the $80 \mathrm{n}$ mile segments are presented in Table 3. The 1st principal component (PC), explaining $31 \%$ of the variance, relates to high sub-surface biomass (mainly zooplankton and mesopelagic fish), as shown by the high loading of the 6 variables measured by the sonar The 2 nd PC, explaining $20 \%$ of the variance, relates to a flat underwater topography, deep water and a great distance from shore. The 3rd PC, explaining $16 \%$ of the variance, contrasts a low deep water biomass with a high chlorophyll concentration. The 1st component can be considered as an index of secondary productivity, the 2nd component as an index of underwater topography and the 3 rd component as a contrast between deep secondary productivity and primary productivity. As the other principal components had eigenvalues less than 1.0 and explained only a small proportion of the variance, they were not investigated any further.

Three of the 4 regions described in the 'Methods' could be well separated on the basis of the first 2 PCs (Fig. 3) Most of the segments belonging to the South American coast region have a positive value of the $1 \mathrm{st}$ $\mathrm{PC}$, suggesting that this region is characterized by a high sub-surface biomass. The 2 nd PC, being as often positive as negative, shows that both very uneven underwater topography and a flat ocean floor occur in this region. The South Pacific gyre is characterized by a low sub-surface biomass and a flat ocean floor. The West Pacific region is mainly characterized by a very high relief. 
Table 3. Relationships between environmental variables over a spatial scale of $80 \mathrm{n}$ miles, using Principal Components Analysis. Variables as in Table 1

\begin{tabular}{|c|c|c|c|}
\hline & \multicolumn{3}{|c|}{ Principal Components } \\
\hline & 1 & 2 & 3 \\
\hline Eigenvalues & 3.132 & 1.970 & 1.614 \\
\hline $\begin{array}{l}\% \text { of total var. } \\
\text { explained }\end{array}$ & 31.320 & 19.703 & 16.139 \\
\hline Intmax 1 & 0.74 & 0.28 & 0.30 \\
\hline Thick1 & 0.69 & 0.16 & 0.31 \\
\hline Intmax 2 & 0.78 & 0.21 & 0.17 \\
\hline Thick2 & 0.59 & 0.33 & 0.41 \\
\hline Intmax 3 & 0.57 & 0.14 & -0.68 \\
\hline Thick 3 & 0.56 & 0.24 & -0.63 \\
\hline Chlconc & -0.17 & 0.03 & 0.59 \\
\hline Meandept & -0.33 & 0.65 & -0.06 \\
\hline C.I. & 0.47 & -0.77 & -0.05 \\
\hline Distland & -0.38 & 0.79 & -0.09 \\
\hline
\end{tabular}

Although the correlation between the first PC and sperm whale density is weak at a spatial scale of $80 \mathrm{n}$ miles, the correlation coefficient increases with increasing spatial scale. At a scale of $320 \mathrm{n}$ miles, there is a substantial positive correlation between the amount of sub-surface biomass and sperm whale distribution (Fig. 2C). This suggests that whales are found in areas of high sub-surface biomass over a spatial scale of about $300 \mathrm{n}$ miles or more. Similarly, the ocean floor topography (2nd PC) seems to have no influence on

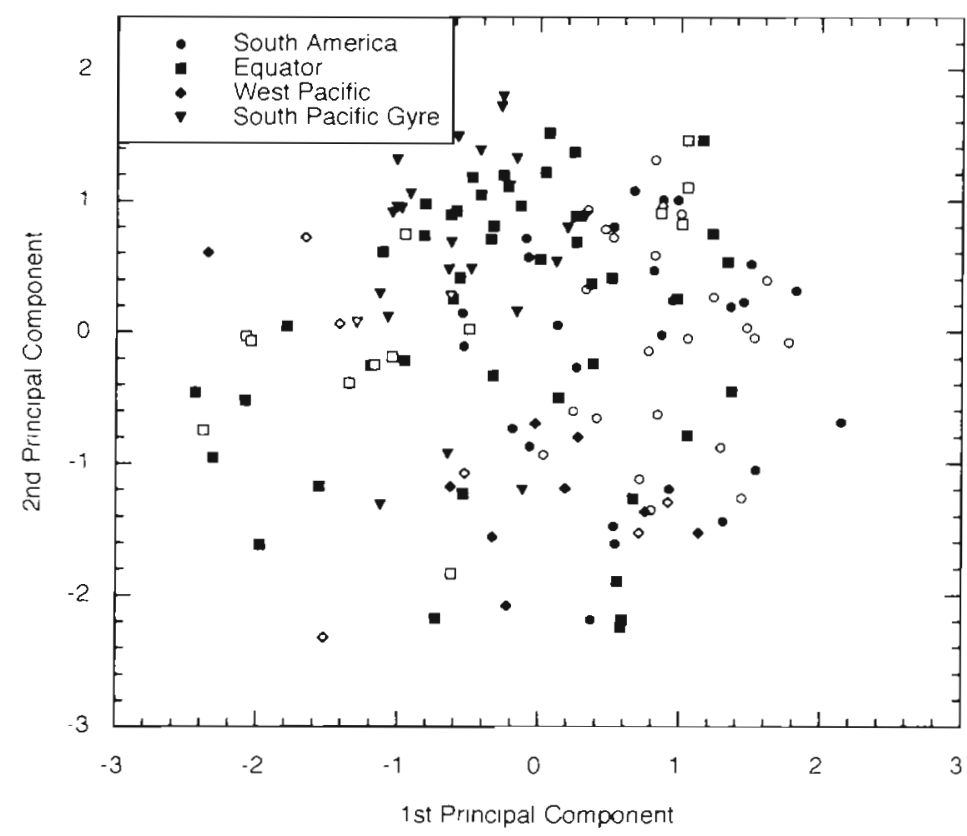

Fig. 3. Scores of the second principal component plotted against the first over a spatial scale of $80 \mathrm{n}$ miles. The open symbols represent the segments where whales were either seen or heard
Table 4. Relationships between environmental variables using Prncipal Compenents Analysis; and value of the Spearman coefficient of correlation $\left(r_{s}\right)$ between the first 4 principal components (PC) and sperm whale density, over a spatial scale of $640 \mathrm{n}$ miles. Variables as in Table 1

\begin{tabular}{|c|c|c|c|c|}
\hline & \multicolumn{4}{|c|}{ Principal Components } \\
\hline & 1. & 2 & 3 & 4 \\
\hline Eigenvalues & 3.954 & 3.061 & 2.163 & 1.757 \\
\hline $\begin{array}{l}\% \text { of tot. var. } \\
\text { explained }\end{array}$ & 26.36 & 20.40 & 14.42 & 11.72 \\
\hline Intmax 1 & 0.587 & 0.632 & -0.328 & 0.045 \\
\hline Thick1 & 0.517 & 0.658 & -0.065 & -0.121 \\
\hline Intmax 2 & 0.482 & 0.732 & -0.142 & -0.071 \\
\hline Thick2 & 0.442 & 0.707 & -0.286 & 0.055 \\
\hline Intmax 3 & 0.731 & -0.133 & 0.493 & -0.178 \\
\hline Thick 3 & 0.682 & -0.027 & 0.573 & -0.119 \\
\hline Chlconc & -0.203 & 0.335 & -0.351 & 0.049 \\
\hline$S S T$ & -0.578 & 0.251 & -0.077 & -0.650 \\
\hline DifinSST & 0.066 & -0.215 & 0.150 & -0.556 \\
\hline Stmax & 0.422 & -0.094 & 0.199 & -0.655 \\
\hline Depth $\Delta t$ & 0.497 & -0.238 & 0.083 & 0.625 \\
\hline Gradient & 0.800 & -0.340 & 0.169 & 0.044 \\
\hline C.I. & -0.416 & 0.532 & 0.611 & 0.099 \\
\hline Distland & 0.433 & -0.579 & -0.514 & 0.037 \\
\hline $\begin{array}{l}\text { Value of } r_{S} \text { between } \\
\text { denswhal and each } P C\end{array}$ & $C^{0.156}$ & 0.461 & 0.454 & 0.055 \\
\hline
\end{tabular}

whale distribution over small spatial scales $(80$ and $160 \mathrm{n}$ miles), but has an effect over spatial scales of at least 320 n miles. However, the third PC shows little or no correlation with sperm whale distribution over the 3 spatial scales. Therefore, over a scale of $80 \mathrm{n}$ miles and when the first 2 PCs are considered, there is no obvious difference between representations of the segments where sperm whales were or were not found (Fig. 3).

For the $640 \mathrm{n}$ miles spatial scale, 4 PCs had large eigenvalues and were therefore considered (Table 4 ). The first PC, which accounts for $26 \%$ of the variance, relates to a high surface and deep biomass, a high gradient of temperature in the first $100 \mathrm{~m}$ and a low sea surface temperature. The second $\mathrm{PC}$ relates to a high surface and medium biomass, a high relief and a short distance to land. The third PC relates to a high deep biomass, a high relief and a short distance to land. The fourth PC relates to a weak and deep thermocline, a low sea surface temperature and little difference in temperature between consecutive segments. There is only a weak correlation between the 1st PC and sperm whale density, and no correlation between sperm whale density and the 4 th PC (Table 4). However, there is a substantial positive correlation between sperm whale density and the 
second and the third PC, suggesting that sperm whale distribution is correlated with a strong relief and a high subsurface biomass at a spatial scale of $640 \mathrm{n}$ miles.

\section{DISCUSSION}

The sperm whale distribution that we observed in the South Pacific in 1992 to 1993 has much in common with the distribution of the 19th century sperm whale catches (Townsend 1935). High densities of sperm whales were found along the west coast of South America, 'On the Line' between Christmas Island and the Phoenix Islands, along the Tonga archipelago and on the 'Vasquez Ground'. However, only a single sperm whale was heard on the 'Offshore Ground' and on the 'On the Line Ground' between the Galápagos and the Marquesas. This last result was very unexpected as high densities of sperm whales were known to inhabit this area year round during the 19 th century (Maury 1852, Townsend 1935, Berzin 1978, Shuster 1983). Since 1992 was a highly productive year in the Equatorial Pacific (R. T. Barber pers. comm.), the El Niño Southern Oscillation cannot be an explanation for the paucity of whales during summer 1992. No obvious explanation could be found, and other surveys would be necessary to determine if the scarcity of sperm whales in this area is a real and constant phenomenon and, if so, to what cause it could be attributed.

Three of the 4 regions described in the 'Methods' were meaningfully segregated by the 2 first PCs (over spatial scales of 80 to $640 \mathrm{n}$ miles): high productivity in the East Pacific; low productivity and flat ocean floor within the gyre; high C.I. and variable productivity in the West Pacific. The equatorial region was more difficult to characterize as there is a gradient of productivity from west to east and a gradient of sea surface temperature and of depth of the mixed layer from east to west.

The statistical analyses of the relationships between whale density and environmental features were very consistent: no substantial correlation at a spatial scale of $80 \mathrm{n}$ miles, and an increased correlation with increasing spatial scale for every variable concerned. Moreover, correlation analyses and principal component analyses gave similar results. This suggests that the results are meaningful, and that the pattern can be interpreted even if no significance tests could be done due to strong autocorrelation, multiple correlation tests, and non-normality of the PCA variables.

Over large spatial scales (320 to 640 n miles), sperm whales were fomnd in regions of high relief and close to land. This is consistent with the work of Clarke (1956) who showed that sperm whales seem to be especially attracted to oceanic islands where volcanism has raised the land sheer from the depth. He postulated that the upthrust of volcanic peaks causes vertical mixing which breaks down discontinuity layers and allows a local increase in organic production. S. Gowans \& S. Hooker (pers. comm.) failed to detect any correlation between sperm whale density and a high relief around the Galápagos Islands. However, they only used spatial scales of $10 \times 10,15 \times 15$ and $30 \times 30 \mathrm{n}$ miles, and the absence of correlation at such small scales is consistent with our results.

Several authors have noted an association between sperm whale density and areas of high primary productivity (Townsend 1935, Caldwell et al. 1966, Gulland 1974). However, no attempts have been made to understand the scale of the relationship. In our results, chlorophyll concentration was not closely related to sperm whale distribution, at any spatial scale. Vinogradov (1981) demonstrated that the development of all trophic levels between phytoplankton and large squid takes approximately $4 \mathrm{mo}$, and thus a peak in chlorophyll concentration is temporally and probably spatially separated from a peak in squid density. Therefore, it might be difficult to detect a relationship between sperm whale distribution and phytoplankton concentration without averaging the data over temporal scales of at least several months.

The present study shows that the amount of sub-surface biomass is closely related to sperm whale distribution. The correlation analyses suggest that sperm whale density is more closely related to the amount of biomass in the medium layer ( 50 to $300 \mathrm{~m}$ ) than to the amount of biomass in the deep layer (300 to $600 \mathrm{~m}$ ), and that there is only a very weak correlation between sperm whale density and the amount of surface biomass $(0$ to $50 \mathrm{~m}$ ). Most of the organisms forming the scattering layers undertake vertical diel migrations, and thus the depth of the scattering layers is strongly related to the time of day at which the observations are made. Therefore, if the observations had been made at another time of day or night, it is possible that sperm whale density would be more closely correlated with the deep or the surface layer than with the medium layer as in the present case. However, the PCA do not discriminate between depth. The first PC (for 80, 160 and. $320 \mathrm{n}$ miles spatial scale) has high loading for every variable describing the amount of sub-surface biomass, regardless of the depth. At a spatial scale at $640 \mathrm{n}$ miles: both the 2 nd and the $3 \mathrm{rd}$ PC have about the same correlation coefficient with sperm whale density, even thought the 2 nd represents a high surface and medium layer biomass while the $3 \mathrm{rd}$ represent a high deep layer biomass. The correlation between sperm whale density and sub-surface blomass is consistent with Berzin (1971) who postulated that sperm whales are found in areas with a high density of deep 
water fauna, and that the development of this fauna is optimum in downwelling regions. However, he gave no indication of the spatial scale involved. Our results, using both correlation analyses and PCA, indicate that the association between sperm whale density and amount of sub-surface biomass occurs only at spatial scales equal to or greater than about $320 \mathrm{n}$ miles

In contrast to the work of Gaskin (1973) and to Ramirez \& Urquizo (1985), our study failed to detect the possible impact of the gradient of temperature and of the surface temperature on sperm whale distribution. Due to funding constraints, only 55 XBTs were launched during the entire survey. It is likely that such a low number, in comparison to the large area investigated, was insufficient to detect anything but a very strong relationship. Since groups of female sperm whales are found at every latitude from $0^{\circ}$ to $40^{\circ}$ and in every ocean of the world, it is clear that they are found at a very wide range of sea surface temperatures (SST). Thus, to detect the possible influence of SST on sperm whale distribution, it would be important to investigate one rather homogenous region at a time instead of the entire South Pacific. However, in the present study, the data were not sufficient to allow discrete analyses over each region.

Therefore, our results suggest that groups of female sperm whales are generally distributed within large areas (320 to $640 \mathrm{n}$ miles) characterized by high secondary productivity and steep underwater topography. The size of these areas may reflect the distance over which groups of female sperm whales move in search of food. This is consistent with the work of Dufault \& Whitehead (1995), who compared individual identifications from fluke pictures of sperm whales taken during the South Pacific survey to our extensive fluke catalogue from the Galápagos Islands, and found that a whale was never seen more than $600 \mathrm{n}$ miles from the location where it had been first identified. Similarly, during the 'Discovery' campaign of marking sperm whales, undertaken between 1950 and 1975, the mean distance between marking and capture for female sperm whales was $372 \mathrm{n}$ miles (Best 1979).

The absence of correlation between sperm whale density and environmental features or productivity over smaller spatial scales may indicate that factors other than food resources influence sperm whale distribution over these scales. However, feeding requirements could still have an important influence on sperm whale distribution at smaller spatial scales, but may not have been detected for 2 main reasons. Firstly, there is a space lag between the position of large meso- and bathypelagic cephalopods and the location of zooplankton (Vinogradov 1981). Therefore, if the distance between high biomass of zooplankton and high density of squids is larger than the spatial scale investigated, correlation analyses will show no association between sperm whale and secondary productivity, wrongly suggesting that food resources are of no importance over these scales. Secondly, due to their large size, sperm whales could fast or eat very little for periods of weeks without being affected (Brodie 1975). Therefore, it may be advantageous for them to 'commute' from one small area of very high cephalopod density to the next one, as soon as the first area is depleted. During their 'commuting' they would still be foraging, but their feeding success would be much lower. Even thought we did not have enough data to relate feeding success (using the measure of Smith \& Whitehead 1993) to productivity variables during this study, we observed that feeding success was very variable between encounters. Thus, a certain proportion of whale encounters could have happened while groups were 'commuting', which would explain the absence of correlation over small spatial scales.

Acknowledgements. We thank the crew of 'Balaena' who helped collecting the data at sea and especially S. Childerhouse, S. Dufault, K. Freemantle, D. McCutchen and L. Weilgart. This study was funded by the National Geographic Society, the Natural Sciences and Engineering Research Council of Canada, and Cetacean Society International. N.J was supported by the Izaak Walton Killam Memorial Scholarship, the Roche Research Foundation, the 'Société Académique Vaudoise', the 'Basler Stiftung für biologische Forschung', and the 'Fondation Janggen-Poehn' Equipment was donated and loaned by John Fentress, Satlantic, Benthos Ltd and Ilford Canada. The following organizations kindly gave us permission to work in their waters and assisted in other ways: the Armada of Ecuador, the Galápagos National Park Service, the Charles Darwin Station, the Haut-Commissanat de la République en Polynésie Française, the Department of Conservation New Zealand, and the Armada of Chile. We were helped considerably during our port calls by David Gaynor, Tri-County Marine, Godfrey Merlen, Gayle Davis, Michael Poole, the staff of the Richard Gump Biological Station, John Childerhouse, Elizabeth Slooten, Stephen Dawson, Hannah Moore, Michael Moore, and many others. The manuscript was much improved by comments from R. O'Dor, I. McLaren, $R$. Scheibling and 3 anonymous reviewers.

\section{LITERATURE CITED}

Backus RH, Schevill WE (1966) Physeter clicks. In: Norris KS (ed) Whales, dolphins and porpoises. Univ of Calif Press, Berkeley, p 510-527

Bakun. A, Csirke J (in press) Environmental processes potentially involved in recruitment variability of Illex squids. In: Dawe EG, Rodhouse PG, O'Dor RK (eds) Squid recruitment dynamics: influences on variability within the genus Illex. FAO Fish Tech Pap, Rome

Berzin AA (1971) The sperm whale. In: Yablokov AV (ed) Pischevaya Promyshlennost, Moscow (translation by Israel Program for Scientific translations, Jerusalem)

Berzin AA (1978) Whale distribution in Tropical Eastern Pacific waters. Rep Int Whal Commn 28:173-177

Best PB (1979) Social organization in sperm whales, Physeter macrocephalus. In: Winn HE, Olla BC (eds) Behavior of 
marine animals, Vol 3, Cetaceans. Plenum Press, NewYork, p 227-289

Brodie PF (1975) Cetacean energetics, an overview of intraspecific size variation. Ecology 56:152-161

Caldwell KD, Caldwell MC, Rice DW (1966) Behavior of the sperm whales, Physeter catodon. In: Norris KS (ed) Whales, dolphins and porpoises. Univ of Calif Press, Berkeley, p 677-717

Clarke MR (1966) A review of the systematics and ecology of oceanic squids. Adv Mar Biol 4:91-300

Clarke MR (1980) Cephalopods in the diet of sperm whales of the Southern Hemisphere and their bearing on sperm whale biology. 'Discovery' Rep 37:1-324

Clarke MR (1985) Cephalopod biomass-estimation from predation. In Boyle PR (ed) Cephalopod life cycles, Vol 2, Comparative reviews. Academic Press, London, $p$ 221-237

Clarke MR, Lu CC (1974) Vertical distribution of cephalopods at $30^{\circ} \mathrm{N}$, and $20^{\circ} \mathrm{W}$ in the North Atlantic. J Mar Biol Ass UK 54:969-984

Clarke MR, Martins HR, Pascoe P (1993) The diet of sperm whale (Physeter macrocephalus) of the Azores. Phil Trans R Soc Lond B 339:67-82

Clarke R (1956) Sperm whales off the Azores. 'Discovery' Rep 28:239-298

Dufault S, Whitehead H. (1995) The geographic stock structure of female and immature sperm whales in the South Pacific. Rep Int Whal Commn 45:401-405

Farrweather PG (1988) Correlations of predatory whelks with intertidal prey at several scales of space and time. Mar Ecol Prog Ser 45:237-243

Flury B, Riedwyl H (1988) Multivarlate statistics, a practical approach. Chapman and Hall, London

Gaskın DE (1968) Analysis of sightings and catches of sperm whales (Physeter catodon) in the Cook Strait area of New Zealand in 1963-4. NZ J Mar Freshwat Res 2:260-272

Gaskin DE (1973) Sperm whales in the Western South Pacific. NZ J Mar Freshwat Res 7:1-20

Gordon JC (1987) The behaviour and ecology of sperm whales off Sri Lanka. PhD thesis, Darwin College, University of Cambridge

Green RE (1967) Relationship of the thermocline to success of purse seining for tuna. Trans Am Fish Soc 96:126-130

Greenblatt PR (1979) Associations of tuna with floatsam in the eastern tropical Pacific. Comml Fish Rev 32(1):147-155

Gulland JA (1974) Distribution and abundance of whales in relation to basic productivity. In Schevill WE (ed) The whale problem. Harvard University Press, Cambridge, MA, p 27-52

Hui CA (1979) Undersea topography and distribution of dolphins of the genus Delphinus in the southern California Bight. J Mamm 60(3):521-527

Kenney RD, Winn HE (1987) Cetacean biomass densities near submarine canyons compared to adjacent shelf/slope areas. Cont Shelf Res 7(2):107-114

Lu CC, Clarke MR (1975) Vertical distribution of cephalopods

This article was submitted to the editor at $40^{\circ} \mathrm{N}, 50^{\circ} \mathrm{N}$ and $60^{\circ} \mathrm{N}$ and $20^{\circ} \mathrm{W}$ in the North Atlantic. J Mar Biol Ass UK 55:143-163

Maury MF (1852) Wind and current charts. Whale sheets number 1 to 4 , series F. Washington

McLean SD, Lewis MR (1991) An expendable spectral radiometer drifter system (ESR). Proc IEEE Oceans 91 Symposium, IEEE Press, p 831-834

Murphy GI, Shomura RS (1972) Pre-exploitation abundance of tunas in the equatorial central Pacific. Fish Bull US $70(3): 875-905$

Papastavrou V, Smith SC, Whitehead H (1989) Diving behaviour of the sperm whale (Physeter macrocephalus) off the Galápagos Islands. Can J Zool 67:839-846

Ramirez P, Urquizo W (1985) Los cetaceos mayores y el Fenomeno 'EL Niño' 1982-1983. Instituto del Peru, Boletin (volumen extraordinario) 'El Niño, su impacto en la fauna marina', Callao, Peru, p 201-206

Rice DW (1989) Sperm whales (Physeter macrocephalus). In: Ridgway SH, Harrison R (eds) Handbook of marine mammals, Vol 4. Academic Press, London, p 177-233

Schneider DC, Piatt JF (1986) Scale-dependent correlation of seabirds with schooling fish in a coastal ecosystem. Mar Ecol Prog Ser 32:237-246

Selzer LA, Payne PM (1988) The distribution of white-sided (Lagenorhynchus acutus) and common dolphins (Delphinus delphis) vs. environmental features of the continental shelf of the northeastern United States. Mar Mamm Sci $4(2): 141-153$

Shuster GW (1983) The Galápagos Islands: a preliminary study of the effects of sperm whaling on a specific whaling ground. Rep Int Whal Comm Special lssue 5:81-82

Smith SC, Whitehead H (1993) Variation in the feeding success and behaviour of Galapagos sperm whales (Physeter macrocephalus) as they relate to oceanographic conditions. Can J Zool 71:1991-1996

Sokal RR, Rohlf FJ (1981) Biometry. Freeman, San Francisco

Sutcliffe $W H$, Brodie PF (1977) Whale distributions in Nova Scotia waters. Fish Mar Serv Tech Rep 722:1-89

Townsend $\mathrm{CH}$ (1935) The distribution of certain whales as shown by logbook records of American whalerships. Sci Contr New York Zool Soc, Zoologica 19(1):1-50

Uda M (1959) The fisheries of Japan. Nanaimo Biological Station, Fish Res Bd Can

Viale D (1991) Une méthode synoptique de recherche des zones productives en mer: détection simultanée des cétacés, des fronts thermiques et des biomasses sousjacentes. Ann Inst Oceanogr, Paris 67(1):49-62

Vinogradov ME (1981) Ecosystems of equatorial upwellings. In: Longhurst AR (ed) Analysis of marine ecosystems. Academic Press, London, p 69-94

Volkov AF, Moroz IF (1977) Oceanological conditions of the distribution of cetacea in the eastern tropical part of the Pacific Ocean. Rep Int Whal Commn 27:186-188

Whitehead H, Brennan S, Grover D (1992) Distribution and behaviour of male sperm whales on the Scotian Shelf, Canada. Can J Zool 70:912-918

Manuscript first received: August 22, 1995

Revised version accepted: November 25, 1995 